ods. Farming Systems Support Proj. 1983. Univ. of Florida, Gainesville.

Rojas, M.H. 1984. Analyzing "sondeo" interviews from farming systems research. Virginia
Polytechnic Inst. and State Univ., Blacksburg. (Monograph.)

Schuh, G.E. 1984. Revitalizing the land grant university. Colloq., Strategic Mag. Res. Ctr., Univ. of Minnesota, St. Paul, Minn. (Mimeo).

Shaner, W.W. 1982. Farming systems research and development: guidelines for developing countries. Westview, Boulder, Colo.

\section{Teaching the Principles of Landscape Bidding with an Electronic Spreadsheet}

\author{
David J. Beattie ${ }^{1}$ and Lawrence C. Ragan ${ }^{2}$ \\ The Pennsylvania State University, University Park, PA 16802 \\ Additional index words. computerized bidding, landscape estimating, computer-aided \\ instruction
}

Abstract. An interactive spreadsheet program was developed to demonstrate how a landscape bid is estimated. Information from a profit and loss statement, entered periodically, is retained for succeeding bids. Machine and labor costs are determined separately. For an individual bid, inputs include cost of materials, overhead, labor and machine times, contingency, and profit. Labor costs are automatically modified to reflect crew efficiency, and materials costs reflect storage, freight, and other charges. Overhead is based on the relationship between annual direct and indirect costs. The calculations section displays intermediate steps of the final bid estimate. Summaries from calculations include a final bid estimate. A printing option allows the user to selectively print any of the sections, a customer's copy, or the entire bid. The program uses an Apple Macintosh computer, was written for Microsoft Excel software, and uses macro programs. Its concept can be adapted to any electronic spreadsheet and can be protected to allow entry of only certain input data. The program can be used for small landscape businesses, classroom instruction, and/or extension instruction in which higherorder thinking skills are emphasized.

Students today are exposed, particularly outside the classroom, to a wealth of visual stimuli, including movies, television, video tapes, video disks, and computerized video games. These visual stimuli have become such an integral part of students' lives that the traditional lecture format that served classroom instruction for past generations may be dull and ineffective by comparison. Consequently, teachers are using these media, particularly computer-aided instruction, in their classrooms to make instruction challenging, as well as informative. Interactive computer programs can stimulate student interest and reduce rote learning while concentrating on higher-order thinking processes, such as making management decisions (Hannafin and Peck, 1988; McKeachie, 1986).

The primary objective of any landscape business should be to make a satisfactory profit. Most landscape bids are developed by

Received for publication 20 July 1989. Contribution no. 146 Dept. of Horticulture. Authorized for publication as Paper no. 8180 in the Journal Series of the Pennsylvania State Univ. Agricultural Experiment Station. The cost of publishing this paper was defrayed in part by the payment of page charges. Under postal regulations, this paper therefore must be hereby marked advertisement solely to indicate this fact.

${ }^{1}$ Assistant Professor, Dept. of Horticulture.

${ }^{2}$ Instructional Designer, Computer Based Education Laboratory. using the "rule of thumb" method, where the estimate of how much will be charged for landscape services is arrived at by multiplying plant and/or material costs by 2 or 3. While this may be further modified by labor costs, site considerations, or travel time, the estimating process is usually unstructured. For an established business, the rule- of-thumb method that has been developed and refined with many years of experience may be adequate. However, this bid method may not reflect the actual direct and indirect (overhead) costs, nor can costs be identified with any particular activity. As a result, the desired profit margin is not known. When the actual costs are not known it is also difficult to modify the bid. In addition, the "ruleof-thumb" for one business does not apply to another business.

Computer-aided instruction has been used in teaching agricultural courses (Barbarick, 1985; Danneberger and Rieke, 1985; Dekkers and Donatti, 1981; St. Martin and Skavaril, 19894), for management simulations (Johnson et al., 1984; Russell, 1985), and plant identification (Porkorny, 1988). However, few interactive computerized spreadsheets have been developed for landscape bidding (Smith, 1986); none are for the Macintosh. This spreadsheet bidding program is designed to assist students in understanding how a landscape bid is structured and how costs are allocated so that reasonable profits are ensured and so that management decisions can be made on correct and accurate information.

The objectives of this interactive bidding program are to: 1) Prepare a landscape bid based on actual direct and indirect costs. 2) Ensure a realistic profit margin. 3) Determine annual direct and indirect cost adjustment factors and periodically update overhead costs. 4) Adjust costs based on labor efficiency, unproductive time, and unforeseen contingencies. 5) Allow the user to adjust or update bid factors and costs without tedious

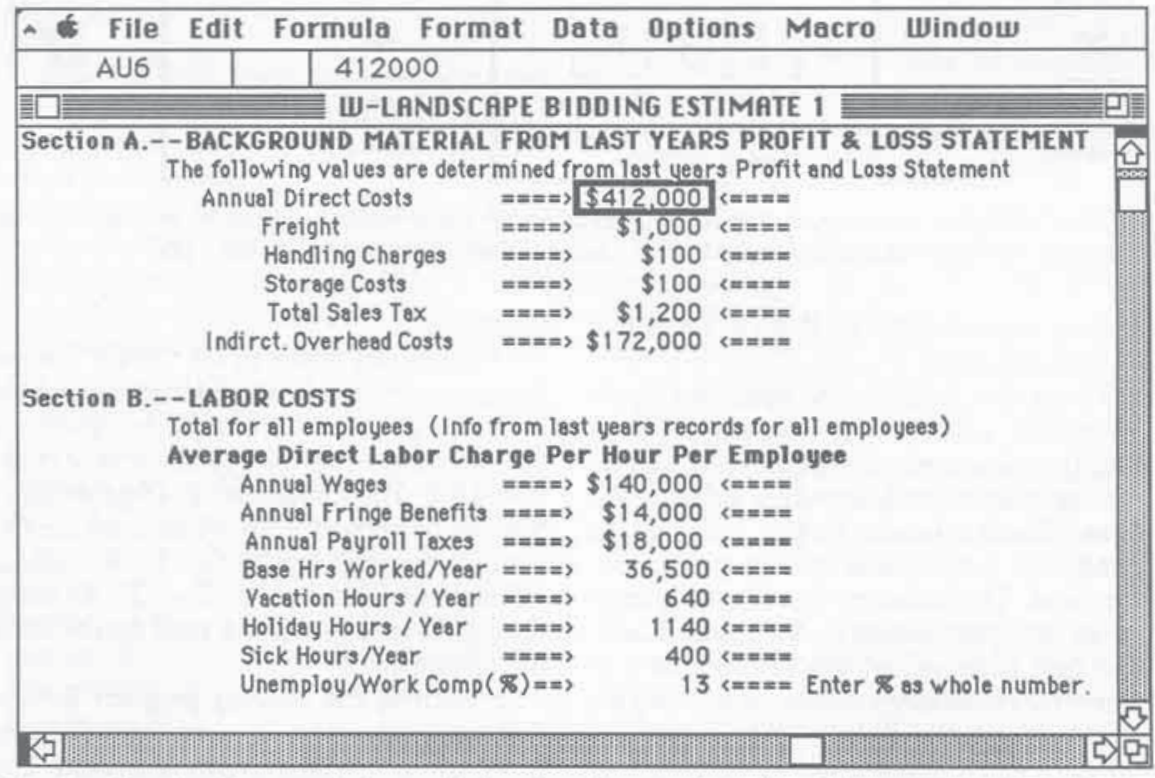

Fig. 1. Completed entry path for yearly data from last year's profit and loss statement. 


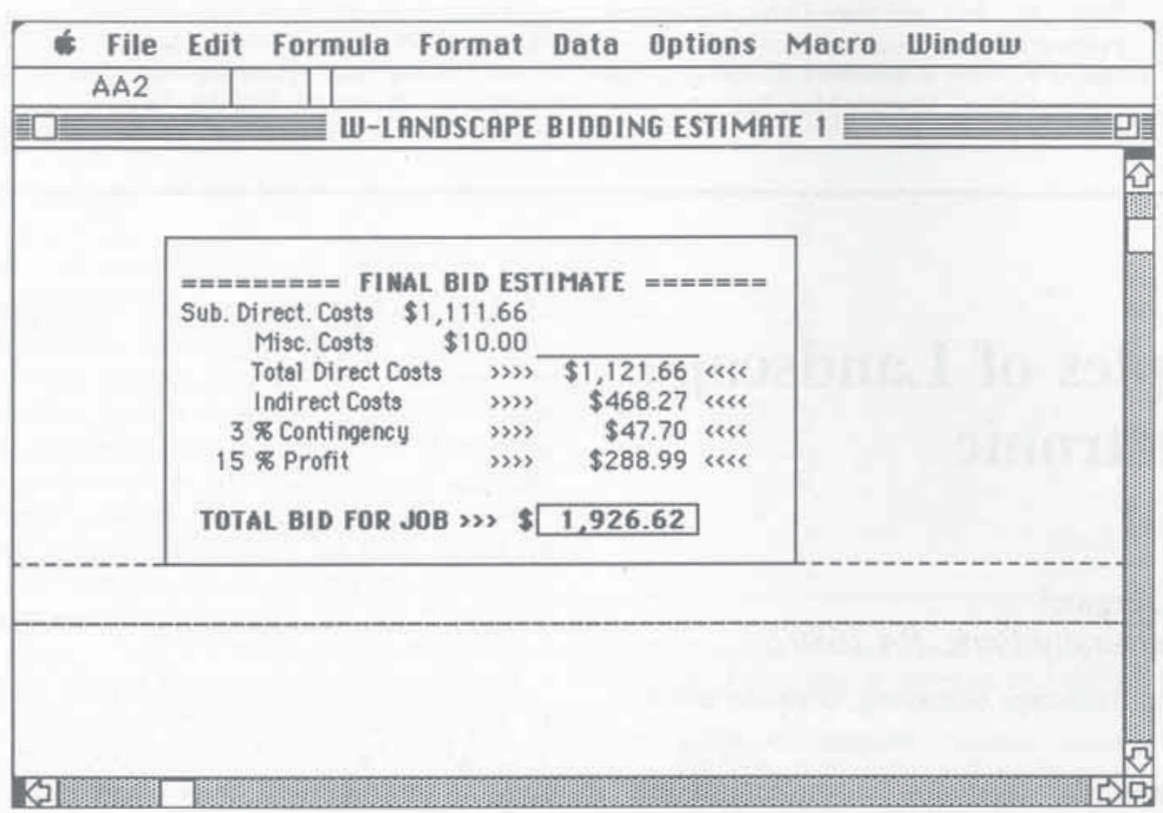

Fig. 2. The completed final bid estimate, which is part of the results section, is calculated automatically.

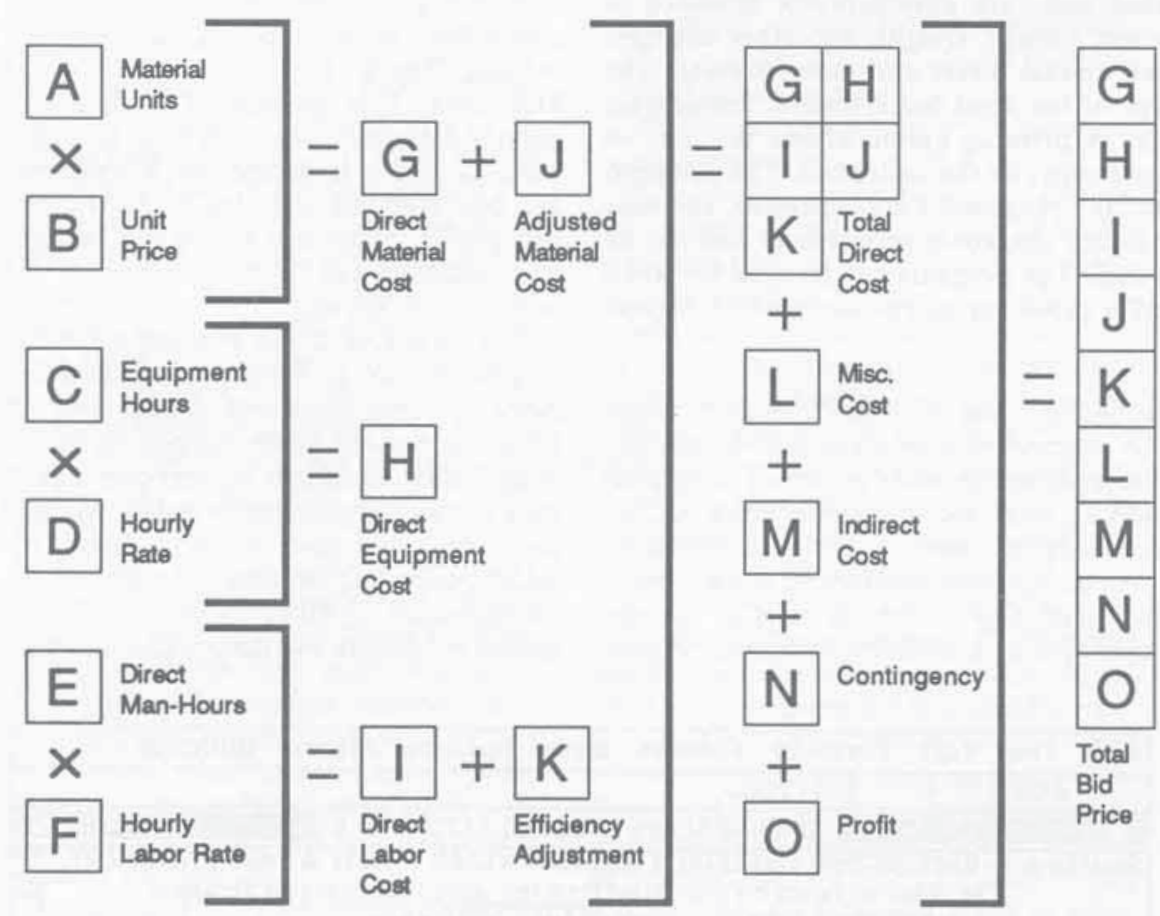

Fig. 3. Complete landscape bid structure, including all input values, adjustment and contingency factors, and their relationship to each other. Adapted from Jensen and Kirschling (1976).

manual recalculation. 6) Reduce errors due to miscalculations.

To use this program one needs: an Apple Macintosh computer (minimum $512 \mathrm{~K}$ of RAM) with one external disk drive, an Apple Imagewriter or Laserwriter printer, Microsoft Excel software (version 1.5), and the Landscape Bid Estimate Startup disk and instructions. The landscape bid estimate is made up of two documents in Microsoft Excel. The first is the actual spreadsheet that performs the calculations necessary to complete the Landscape Bid Estimate. The second Excel document, called a macro program, allows the user to move quickly from screen to go from one section or menu to another. The mouse is not used for this program. From the input submenu, a choice is made whether to enter yearly input data or job input data just for this bid, or the user can return to the main menu. Yearly input data is information from the profit and loss statement. It may be entered or updated once a year and retained throughout the year or updated periodically. Machine and labor costs are determined separately. Job input data include cost of materials, labor and machine times, contingency, and profit. Labor costs are automatically modified to reflect crew efficiency. Materials costs are modified automatically to reflect storage, freight, and other associated charges. Overhead is allocated based on the relationship between annual direct and indirect costs. The complete bid structure is illustrated in Fig. 3. Note when an input option is chosen, an entry pathway is automatically activated to accept data.

Information must be entered into both input sections, "Yearly Data For Operation" and "Data for this Bid", for the program to operate properly. Once these sections have been completed, calculations are automatically made and transferred from the Calculations section to the Results section, which contains the Final Bid Estimate. The Final Bid Estimate contains the results of calculations, as well as a print macro that allows the user to selectively print any section.

The following are descriptions of the individual elements in the Input, Calculations, and Results sections.

\section{INPUT DESCRIPTIONS}

\section{Yearly data for operation}

Yearly Input Section A-Background information. This section contains background information from last year's profit and loss statement, sometimes called the income statement. It combines income from various sources for a specified time period, such as a year, and subtracts from it the total expenses for that period. From this summary statement, records for the preceding year are obtained to make management decisions related to the landscape bid. A new business without records from which to obtain this information may wish to enter an estimate based on industry figures that are available from various sources, such as state and national nursery trade associations.

Information obtained from the profit and loss statement includes: annual direct costs, freight, handling charges, storage costs, total sales tax, and the indirect (overhead) costs.

Yearly Input Section B-Labor costs. Although hourly personnel may be paid at various rates, an average hourly wage is used for all workers for this bid. The elements used to determine this are: annual wages, annual fringe benefits, annual payroll taxes, base hours worked each year, vacation hours per year, holiday hours per year, and sick hours per year. For unemployment and workmen's compensation, the average total percent of the employees' hourly wage rate 
that is paid for both of these expenses is entered.

Yearly Input Section C-Annual machine costs. Machine costs contain some fixed and some variable costs. The cost per hour or distance travelled varies directly with the level of use and is a variable cost, while depreciation is an example of a fixed cost. The fixed part of the machine costs remains constant, while the variable portion generally decreases with increased use. Knowing these actual costs has two advantages: 1 ) the landscape bid can be more competitive, and 2) the machine owner knows whether or not the machine is being used efficiently. For the smaller landscape company, or for the person just starting in business, it may be more practical to use machine costs based on an hourly rental rate for each piece. Then, if the machine is being under-used, renting or contracting for the service from someone else should be considered. Machine costs are calculated on: purchase price, salvage value, estimated life (years), annual use (hours or miles, depending on whether the machine is a tractor or a truck), percent interest on salvage value, fuel cost per gallon, the efficiency of the machine in gallons per hour or miles per gallon used, license (where applicable), repairs and service labor time, and oil, grease, and antifreeze.

\section{Data for each landscape bid}

Bid Section A-Net profit and contingency. When the projected net profit is entered as a percentage, the program automatically calculates its dollar value based on the total bid price. Similarly, when the projected contingency, which adjusts the bid price for particularly long periods of bad weather that may slow work and increase labor costs, is entered as a percentage of the total direct and indirect costs, the program automatically calculates its dollar value.

Bid Section B-Labor costs factors. Factors are numbers or percentages that are multiplied by a number to determine a result. This program allows the user to enter factors for crew efficiency and unproductive time that automatically adjust the labor rate. Crew efficiency, although difficult to determine, can be objectively estimated. Although not always necessary to use, it does give the bidder another tool to fine-tune or make adjustments to the bid.

Bid Section C-Materials. Here the list of the principal plant or hardgood items used for the job, including the material description, quantity, wholesale cost per unit, and the installation labor hours per unit, is entered.

Bid Section D-Machine time to install or plant materials. To determine these costs, the user needs to enter, where applicable, miles for Truck A, miles for Truck B, hours for tractor, hours for rototiller, hours for the tree digger, and hours for other machines.

Bid Section E-Miscellaneous costs. These are the costs of small items used on the job, such as wire, nails, twine, or small quantities of peatmoss that are too small to be adjusted (as the cost of materials are adjusted) so are entered directly; included is the description and cost of each item.

\section{INTERPRETATION OF CALCULATION SECTION}

Calculation Section A-Factors derived from the profit and loss statement. The Direct Cost Adjustment Factor is multiplied by direct costs, such as plant materials. It increases the plant's cost to reflect small, but real costs, related to freight, handling charges, storage costs, and total sales tax. It is assumed that once a business is well established, the percentage relationship between the annual direct costs and the aggregate costs of freight, handling charges, storage, and sales tax will remain constant.

Similarly, the Indirect Cost Adjustment Factor is automatically calculated for each bid. It is difficult to accurately allocate the overhead costs to each bid; therefore, the cost is allocated as a percentage of the annual direct costs to account for managerial or secretarial salaries, office supplies, advertisement, and insurance. It is assumed that once a business is well established the percentage value of this factor will remain fairly constant.

Calculation Section B-Labor costs. Labor costs for each bid are averaged for all full-time and part-time employees. The bid labor cost per hour is the actual wage cost per hour that must be charged in the bid to reflect all the employee costs. It is based on: annual wages, base hours worked per year, unadjusted (for crew efficiency or unproductive time) labor cost per hour, direct labor cost per hour, crew efficiency, and an unproductive time factor.

Calculation Section C-Annual machine costs. For each machine, the total fixed costs and the fixed costs per unit calculations are based on: costs to be recovered, costs recovered, interest on salvage, and insurance.

The total operating costs and the operating costs per unit for each machine include fuel costs, oil, grease, and antifreeze, and repairs.

From the total fixed and operating costs, the bid automatically calculates the total machine cost per year, as well as the total machine cost per unit.

Calculation Section D-Machine costs for materials. Costs related to the installation of plant materials are calculated, identifying the particular item of equipment and hours used. The machine costs to install the material item are then calculated automatically.

This program has enough flexibility to cover most bidding situations. If problems are anticipated, contingency factors can be entered. To develop a bid, it is assumed that complete records and suitable background information are available. The program also assumes some percentages for machine repair and insurance costs. Records of the particular business would probably change these figures.

In summary, although repetition is an im- portant part of instruction, it must be varied and stimulating to be effective. The use of an interactive program for teaching the principles of landscape bidding reduces repetitious work and stimulates students' other cognitive processes. We have used this bidding program (preceded by $\approx 2$ hr of handson instruction on how to use the Macintosh computer) as a stand-alone lesson in horticultural management courses at Penn State. When students use this program, they respond positively; recalculations can be done almost instantaneously, which allows the instructor to focus attention on higher-order thinking. For instance, once students complete the bid, they can develop a sense of how a manager or person in charge of bidding must make decisions by posing "what if' situations: What if the profit percent were changed? What if overhead costs were higher? What if a new machine is purchased? How will the answers to these questions influence my bid?

This program has helped our students to better understand how a landscape bid is structured and how costs are allocated so that reasonable profits are ensured. In addition, once the bid is completed, input data can be changed so management decisions can be made quickly on correct and accurate information. However, the bidding program is designed as an instructional tool, rather than for commercial use. Persons wishing to obtain more information about Landscape Bid Estimate should either send a Macintosh disk to or contact D.J.B.

\section{Literature Cited}

Barbarick, K.A. 1985. Computer assisted learning in introductory soil science. J. Agron. Educ. 14(2):77-80.

Danneberger, T.K. and P.E. Rieke. 1985. Turfagation: A computer simulated water management game for turf. J. Agron. Educ. 14(1):3537.

Dekkers, J. and S. Donatti. 1981. The integration of research studies on the use of simulation as an instructional strategy. J. Educational Res. 74(6):28-32.

Hannafin, M.J. and K.L. Peck. 1988. The design, development and evaluation of instructional software. Macmillan, New York.

Jensen, F.E. and P.J. Kirschling. 1976. Profitable bidding for landscapers. A.E. 363. New Jersey Agr. Expt. Sta.

Johnson, S.D., R.I. Carter, and W.W. Miller. 1984. Using the microcomputer as a decisionmaking aid in teaching farm management. NACTA J. 28(1):4-7.

McKeachie, W.J. 1986. Teaching tips-A guidebook for the beginning college teacher. 8th ed. D.C. Heath and Co., Lexington, Mass. p. 153157, 170-173.

Porkorny, F.A. 1988. Computer-assisted plant identification tests. NACTA J. 32(2):28-30.

Russell, W.C. 1985 . Microcomputers aid instruction in livestock management. NACTA $\mathrm{J}$. 29(4):14-16.

Smith, R.C. 1986. Project costing with microcomputers. HortScience 21(2):322-323.

St. Martin, S.K. and R.V. Skavaril. 1984. Computer simulation as a tool in teaching introductory plant breeding. J. Agron. Educ. 13:43-47. 